\title{
Fisheries impact on the East China Sea Shelf ecosystem for 1969-2000
}

\author{
Yunkai Li $\cdot$ Yuying Zhang
}

Received: 15 March 2011/Revised: 29 August 2011/Accepted: 8 September 2011/Published online: 21 September 2011

(C) Springer-Verlag and AWI 2011

\begin{abstract}
An ecosystem model representing the continental shelf of the East China Sea was fitted to a time series of data available from 1969 to 2000 using Ecopath with Ecosim. We used a process-oriented model to explore the extent to which changes in marine resources and the ecosystem were driven by trophic interactions and fishing activities. Fishing effort was used to drive the model, and observed catches were compared with the predicted catches in modeling. A reduction in the sum of the squared deviations of the observed and predicted catches was used as a metric for calibrating and assessing the goodness-of-fit of the model. Trophodynamic indicators were used to explore the ecosystem's structural and functional changes from 1969 to 2000 . The model's predictions were consistent with observed catches for most functional groups. Trophodynamic indicators suggest a degradation pattern over time: both the mean trophic level of community and a modified version of Kempton's index of biodiversity decreased over the time,
\end{abstract}

Communicated by Arne Malzahn.

Electronic supplementary material The online version of this article (doi:10.1007/s10152-011-0278-8) contains supplementary material, which is available to authorized users.

\section{Y. Li $(\bowtie)$}

The Key Laboratory of Sustainable Exploitation of Oceanic Fisheries Resources, Ministry of Education, Shanghai Ocean University, 999 Huchenghuan Road, Pudong Area,

Shanghai 201306, People's Republic of China

e-mail: Ykli@shou.edu.cn

Y. Li · Y. Zhang

School of Marine Sciences, University of Maine,

Orono, ME 04469, USA while the total flow to detritus and the loss of production due to fishing increased from 1969 to 2000 . Additionally, the ratio of demersal/pelagic abundances decreased as a result of an overall decrease in the abundance of demersal species and increase in pelagic fish in the ecosystem.

Keywords Time-series simulation - Ecopath with Ecosim · Fishing impacts - Ecosystem development . East China Sea Shelf

\section{Introduction}

Fishing activities have altered and degraded marine ecosystems through both direct and indirect effects, and the continental shelves that contribute almost half of primary production on earth and sustain three-quarters of global fishery yields have been focal points of human settlement and marine resource use throughout history (Botsford et al. 1997; Myers and Worm 2003; Lotze et al. 2006). Ecosystem models are complimentary to single-species fisheries models in that they can potentially predict the otherwise unforeseen effects of trophic structure and interactions of population dynamics of different fish species (Christensen et al. 2005; Coll et al. 2006). However, the high degree of complexity, extensive input data requirements, and large uncertainty associated with modeling have kept them from becoming a commonly used tool in stock assessment and fisheries management (Cury and Shannon 2004; Christensen et al. 2005; Fletcher et al. 2005; Coll et al. 2006). How to deal with the uncertainty and make reasonable evaluation and prediction of fishing impacts for ecosystem-based management is still a challenge for the ecosystem modelers. 
Fig. 1 The continental shelf and upper slope area of the East China Sea Shelf. Points represented the survey locations took placed from 1998 to 2001

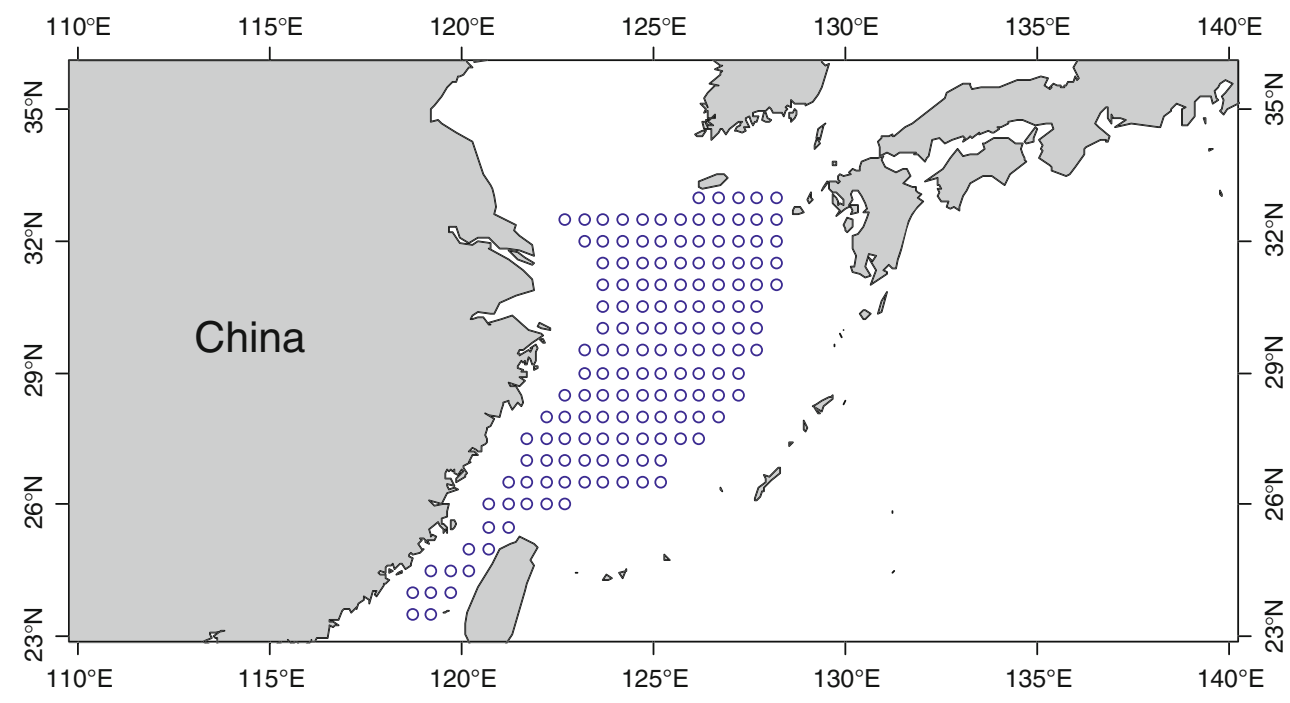

Over the last few decades, East China Sea Shelf (ECSS) has sustained high stress from fishing and pollutions. The total catch and total fishing effort for commercial species have increased significantly (Zheng et al. 2003; Dai 2004; Cheng et al. 2006). Because of prolonged and intense fishing pressure, we observed signs of "fishing through the food web" (Branch et al. 2010) in the ECSS ecosystem. Biodiversity has declined significantly (Cheng et al. 2006). In addition, most large traditional food fish become depleted, and catches are now dominated by small species with high turnover rates (Chao et al. 2005). Moreover, algal blooms were observed more frequently, and the duration of blooming also became longer. Eutrophication resulting from rapid coastal development, industrialization and agricultural development has significant negative impacts on the ecosystem (Xu et al. 2006).

In the previous study (Li 2009), two static ecosystem models of ECSS in two different time periods (1969-1971 and 1998-2001) were constructed, and the characteristic of ecosystem development succession was identified by comparing the two different time period models. The models indicated a large decline in system biomass. Also, biomass and energy flows of the demersal groups reduced greatly from the 1970s to the 2000s, resulting in a shift from being a demersal dominated to a pelagic-dominated system, which has been observed in the composition of the catch consistently with the increasing percentage of landing of the pelagic fishes. In this paper, we simulated the long-term changes on ecosystem structure and functioning of the East China Sea Shelf ecosystem from 1969 to 2000 with the aims of (1) using a dynamic simulation method to evaluate the ecosystem development and the impacts of fishing in ECSS and (2) quantifying the uncertainty for vulnerabilities in Ecosim in evaluating alternative management strategies and evaluate the impacts on ecosystem modeling.

\section{Materials and methods}

Study site

The East China Sea that covers a total area of 750,000 square kilometers is a semi-closed sea lying between the eastern coast of China's mainland and the Pacific Ocean, bounded on the west by China, on the east by the Kyushu and the Ryukyu Islands of Japan, and on the north by Jechu Island of the Republic of Korea and the Yellow Sea, and connected with the South China Sea by the Taiwan Strait on the south (Fig. 1).

The rich fishery resource of the East China Sea makes it the most important fishing ground in the East Asia and one of the most productive fishing grounds in the world (Cheng et al. 2006). Hairtail (Trichiurus haumela), Small yellow croaker (Larimichthys polyactis), large yellow croaker (Pseudosciaena crocea) and cuttlefish (Loligo edulis Hoyle) are the traditional fishing species and contribute nearly half the landings in East China Sea, which have been explored heavily for decades. Total reported landings from the East China Sea increased from less than 1 to over 4.5 million tons from 1950 to the 2000s (Sea Around US project).

\section{Ecopath with Ecosim}

The Ecopath models covering different time periods were constructed for the ECSS (see Appendix in Electronic supplementary material for details). However, ecopath model can only describe static status of an ecosystem, while Ecosim is a dynamic suite which is able to simulate changes in ecosystems, which starts from the static Ecopath model driven by the forcing functions (Walters et al. 1997). It estimates changes of biomass among functional groups 
in the ecosystem as functions of abundance of other functional groups and time-varying catch rates, taking into account predator-prey interactions and foraging behaviors (Christensen et al. 2005). Ecosim is governed by the basic equations:

$\frac{d B_{i}}{d t}=g_{i} \sum_{j=1}^{n} Q j i-\sum_{j=1}^{n} Q i j+I_{i}-\left(M_{i}+F_{i}+e_{i}\right) \cdot B_{i}$

$Q_{i j}=\frac{v_{i j} \cdot a_{i j} \cdot B_{i} \cdot B_{j}}{v_{i j}+v_{i j}^{\prime}+a_{i j}+B_{j}}$

where $\mathrm{d} B_{i} / \mathrm{d} t$ represents the growth rate during the time interval $\mathrm{d} t$ of group $(i)$ in terms of its biomass, $B_{i}, g_{i}$ is the net growth efficiency, $M_{i}$ the non-predation natural mortality rate, $F_{i}$ is fishing mortality rate, $e_{i}$ is emigration rate, $I_{i}$ is immigration rate. $Q_{i j}$ is the consumption of group $j$ organisms by group $i$ organism, $v$ and $v^{\prime}$ parameters represent rates of behavioral exchange between invulnerable and vulnerable states and $a_{i j}$ represents the rate of effective search by predator $j$ for prey type $i$.

Forcing function for time-series simulation

Relative fishing effort was used as the forcing function (Fig. 2). The catch data used here were mainly obtained from the Sea Around Us Project Database (SAUP 2004, http://www.Seaaroundus.org). The biological data were captured during the survey took placed from 1998 to 2001, which covered the whole area of the ECSS (survey location check Fig. 1). The different fishing fleets in the 1970s were integrated into one fleet when doing the time-series simulation due to the lack of detailed information on fishing fleets. Using 1970s model (Appendix) as the starting status,

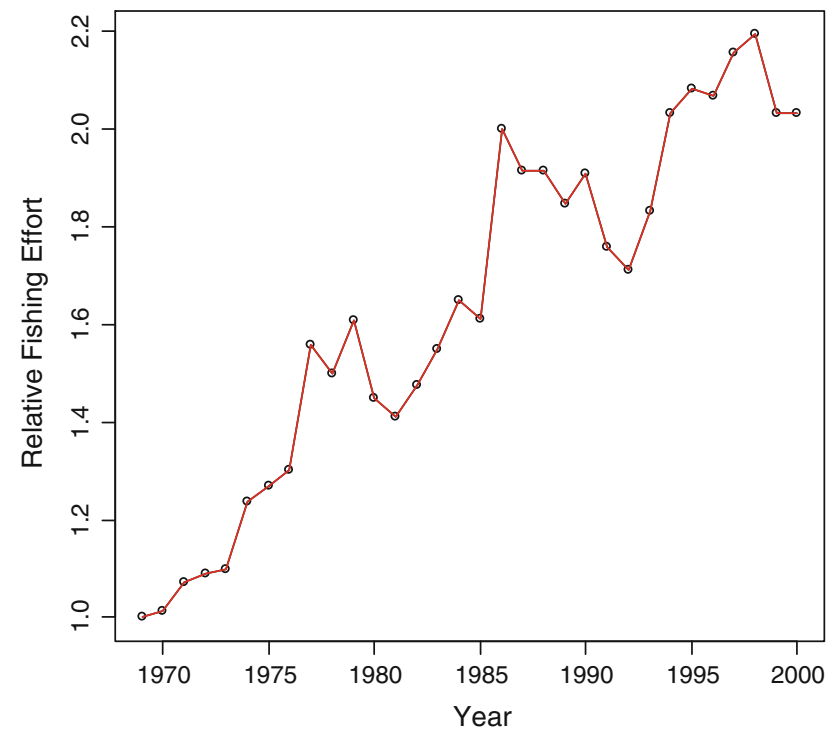

Fig. 2 Forcing function for the time-series simulation we used the fishing effort as the time-series forcing function to do the simulation to fit with time-series data. The fishing efforts were mainly consisted of trawl fishery and purse seine fishery (Liu and Liu 2004). They were integrated using their percentage ratio based on the fishing effort statistics in the annual national fishery statistics (1980-2004).

\section{Vulnerabilities}

Ecosim employs a foraging arena theory to model the feeding behaviors and then to describe how the energy flows that affected by the predator-prey interaction within the ecosystem (Walters and Juanes 1993; Walters and Korman 1999; Walters and Martell 2004). High value of vulnerability means the preys have more probability to be eaten by their predators.

Twenty most sensitive values of the vulnerabilities were searched by fitting the model with the time series, which were determined by Ecosim automatically, which were defined by changing each vulnerability parameter slightly (1\%) then rerunning the model to see how much sum of square is changed. The search iteratively runs the simulation and evaluates the sum of squares, and then it varies the vulnerability parameter and runs the simulation again and looks to see how much the sum of squares has changed. Certain vulnerabilities have a greater impact on the sum of squares (sum of squares is evaluated over all the groups in the model that have time series). The algorithm tests every vulnerability parameter separately (i.e., every trophic linkage) and then tells at the end which were the 20 that

Table 1 Ecosystem indicators applied to the food webs

\begin{tabular}{ll}
\hline Indicator & Definition \\
\hline Q & Total consumption flows in the ecosystem \\
TR & Total Resprision \\
FD & Total flow to detritus \\
TST & Total system throughput, sum of all flows in the food web \\
TLc & Mean trophic level of catch \\
GE & Gross efficiency of fishery \\
Npp & Net primary production \\
Tpp/TR & Total primary production/total respiration \\
NSP & Net system production \\
PP/TB & Primary production/total biomass \\
SOI & System omnivory index \\
FCI & Finn's cycling index \\
FMPL & Finn's mean path length \\
A & The ascendency scaled by TST (related to the average \\
& mutual information in a ecosystem) \\
O & Fraction of internal flows of overhead (used as an \\
& indicator of ecosystem redundancy)
\end{tabular}


had the greatest impact on the sum of squares which were considered as the most critical parameters in the model. In summary, it uses an iterative optimization algorithm to test each linkage independently - the response variable evaluated is sum of squares evaluated over all groups in the model that have time series, and over all simulation years.
The foraging arena theory defines that the probability of an organism to expose to predation risk or to forage safely in its shelter is reflected by a vulnerable coefficient. However, this essential vulnerable coefficient, vulnerability, has never been clearly defined in the user menu. In the version 4 , vulnerability is scaled to range from 0 to 1 , with

Table 2 Modified input parameters and output parameters from the ECSS model

\begin{tabular}{|c|c|c|c|c|c|c|c|c|c|c|}
\hline \multirow[t]{2}{*}{ Functional group } & \multicolumn{5}{|c|}{ 1970s model (1969-1971) } & \multicolumn{5}{|c|}{ 2000s model (1998-2001) } \\
\hline & TL & B & $\mathrm{EE}$ & $\mathrm{P} / \mathrm{Q}$ & $\mathrm{C}$ & $\mathrm{TL}$ & $\mathrm{B}$ & $\mathrm{EE}$ & $\mathrm{P} / \mathrm{Q}$ & $\mathrm{C}$ \\
\hline 1 Marine mammals & 4.00 & 0.026 & $\mathbf{0 . 0 3}$ & 0.01 & 0.00007 & 4.00 & 0.02 & 0.00 & 0.01 & 0.0001 \\
\hline 2 Seabirds & 3.56 & 0.0036 & 0.14 & 0.00 & 0.00007 & 3.56 & 0.0022 & 0.01 & 0.00 & 0.0001 \\
\hline 3 Marine turtles & 3.17 & 0.0033 & 0.066 & 0.30 & 0.000007 & 3.71 & 0.002 & 0.79 & 0.30 & 0.00001 \\
\hline 4 Demersal Sharks and rays & 3.50 & 0.0082 & 0.41 & 0.10 & 0.0020 & 3.50 & 0.01 & 0.90 & 0.10 & 0.003 \\
\hline 5 Pelagic sharks and rays & 4.02 & 0.043 & 0.95 & 0.20 & 0.014 & 4.02 & 0.02 & 0.95 & 0.20 & 0.010 \\
\hline 6 Hairtails(A) & 3.95 & 0.77 & 0.39 & 0.28 & 0.38 & 3.95 & 0.10 & 0.41 & 0.28 & 0.10 \\
\hline 7 Hairtails $(\mathrm{J})$ & 3.90 & 0.15 & 0.68 & 0.21 & 0.10 & 3.90 & 0.25 & 0.51 & 0.21 & 0.28 \\
\hline 8 Large croakers & 3.57 & 0.28 & 0.79 & 0.26 & 0.11 & 3.57 & 0.17 & 0.92 & 0.26 & 0.22 \\
\hline 9 Small croakers & 3.35 & 0.36 & 0.95 & 0.27 & 0.10 & 3.35 & 0.14 & 0.90 & 0.27 & 0.037 \\
\hline 10 Flatfishes & 3.11 & 0.051 & 0.95 & 0.20 & 0.083 & 3.11 & 0.02 & 0.97 & 0.20 & 0.036 \\
\hline 11 Lizardfishes & 3.84 & 0.15 & 0.88 & 0.25 & 0.004 & 3.84 & 0.09 & 0.97 & 0.25 & 0.01 \\
\hline 12 Demersal fishes 1 & 3.47 & 0.29 & 0.95 & 0.27 & 0.014 & 3.47 & 0.13 & 0.95 & 0.27 & 0.02 \\
\hline 13 Demersal fishes2 & 3.11 & 0.65 & 0.95 & 0.26 & 0.087 & 3.11 & 0.31 & 0.94 & 0.26 & 0.43 \\
\hline 14 Demersal fishes3 & 2.92 & 1.24 & 0.95 & 0.20 & 0.66 & 2.92 & 0.56 & 0.95 & 0.20 & 0.19 \\
\hline 15 Snappers & 3.71 & 0.014 & 0.95 & 0.20 & 0.0007 & 3.71 & 0.01 & 0.95 & 0.20 & 0.001 \\
\hline 16 Groupers & 3.73 & $\mathbf{0 . 0 5 0}$ & 0.95 & 0.20 & 0.031 & 3.73 & 0.06 & 0.95 & 0.20 & 0.044 \\
\hline 17 Bigeyes & 3.44 & 0.22 & 0.51 & 0.21 & 0.018 & 3.44 & 0.13 & 0.73 & 0.21 & 0.025 \\
\hline 18 Large reef-associated fishes & 3.55 & 0.062 & 0.95 & 0.30 & 0.0007 & 3.55 & 0.09 & 0.95 & 0.30 & 0.001 \\
\hline 19 Small reef-associated fishes & 2.74 & 0.41 & 0.95 & 0.30 & 0.0021 & 2.74 & $\mathbf{0 . 4 3}$ & 0.95 & 0.30 & 0.003 \\
\hline 20 Large benthopelagic fishes & 3.15 & 0.50 & 0.95 & 0.20 & 0.24 & 3.15 & 0.56 & 0.95 & 0.20 & 0.43 \\
\hline 21 Small benthopelagic fishes & 2.78 & 1.20 & 0.95 & 0.20 & 0.20 & 2.78 & 0.88 & 0.95 & 0.20 & 0.64 \\
\hline 22 Pomfrets & 3.50 & 0.98 & 0.41 & 0.20 & 0.19 & 3.50 & 0.51 & 0.78 & 0.20 & 0.29 \\
\hline 23 Threadfin bream & 3.28 & 0.56 & 0.50 & 0.28 & 0.073 & 3.28 & 0.34 & 0.83 & 0.28 & 0.32 \\
\hline 24 Large pelagic fishes & 3.37 & 0.69 & 0.12 & 0.22 & 0.039 & 3.37 & 0.42 & 0.87 & 0.22 & 0.45 \\
\hline 25 Small pelagic fishes & 2.78 & 2.91 & 0.76 & 0.25 & 0.27 & 2.78 & 1.77 & 0.83 & 0.25 & 0.77 \\
\hline 26 Cephalopods & 3.29 & 1.28 & 0.58 & 0.27 & 0.19 & 3.29 & 0.78 & 0.87 & 0.27 & 0.42 \\
\hline 27 Crabs & 2.42 & 1.02 & 0.48 & 0.25 & 0.029 & 2.42 & 0.62 & 0.71 & 0.25 & 0.23 \\
\hline 28 Shrimps & 2.31 & 0.71 & 0.95 & 0.19 & 0.046 & 2.31 & 0.66 & 0.95 & 0.19 & 0.42 \\
\hline 29 Molluscs & 2.18 & 9.63 & $\mathbf{0 . 5 3}$ & 0.27 & 0.20 & 2.18 & 9.51 & 0.40 & 0.27 & 0.31 \\
\hline 30 Benthic crustaceans & 2.20 & 2.63 & 0.56 & 0.24 & 0.014 & 2.20 & 1.60 & 0.77 & 0.24 & 0.042 \\
\hline 31 Echinoderms & 2.33 & 5.69 & 0.41 & 0.32 & 0.0028 & 2.33 & 3.46 & 0.43 & 0.32 & 0.0010 \\
\hline 32 Polychaetes & 2.00 & 5.14 & 0.62 & 0.28 & - & 2.00 & 3.13 & 0.87 & 0.28 & - \\
\hline 33 Other invertebrates & 2.60 & 4.64 & 0.95 & 0.11 & - & 2.60 & 4.16 & 0.79 & 0.11 & 0.0030 \\
\hline 34 Jellyfish & 2.94 & 0.88 & 0.95 & 0.20 & 0.0085 & 2.94 & 0.38 & 0.95 & 0.20 & 0.060 \\
\hline 35 Zooplankton & 2.00 & 8.06 & 0.48 & 0.17 & 0.0071 & 2.00 & 4.57 & 0.61 & 0.17 & 0.095 \\
\hline 36 Benthic producer & 1.00 & 7.83 & 0.51 & - & 0.0057 & 1.00 & 7.83 & 0.40 & - & 0.0080 \\
\hline 37 Phytoplankton & 1.00 & 13.60 & 0.58 & - & - & 1.00 & 16.85 & 0.31 & - & - \\
\hline 38 Detritus & 1.00 & 10.00 & 0.41 & - & & 1.00 & 10.00 & 0.23 & - & \\
\hline
\end{tabular}

TL, trophic level; B, biomass $\left(\mathrm{t} \mathrm{km}^{-2}\right)$; EE, ecotrophic efficiency; $\mathrm{P} / \mathrm{Q}$, production/consumption; $\mathrm{C}$, catch $\left(\mathrm{t} \mathrm{km}^{-2}\right)$. Values in bold are estimated by the model 

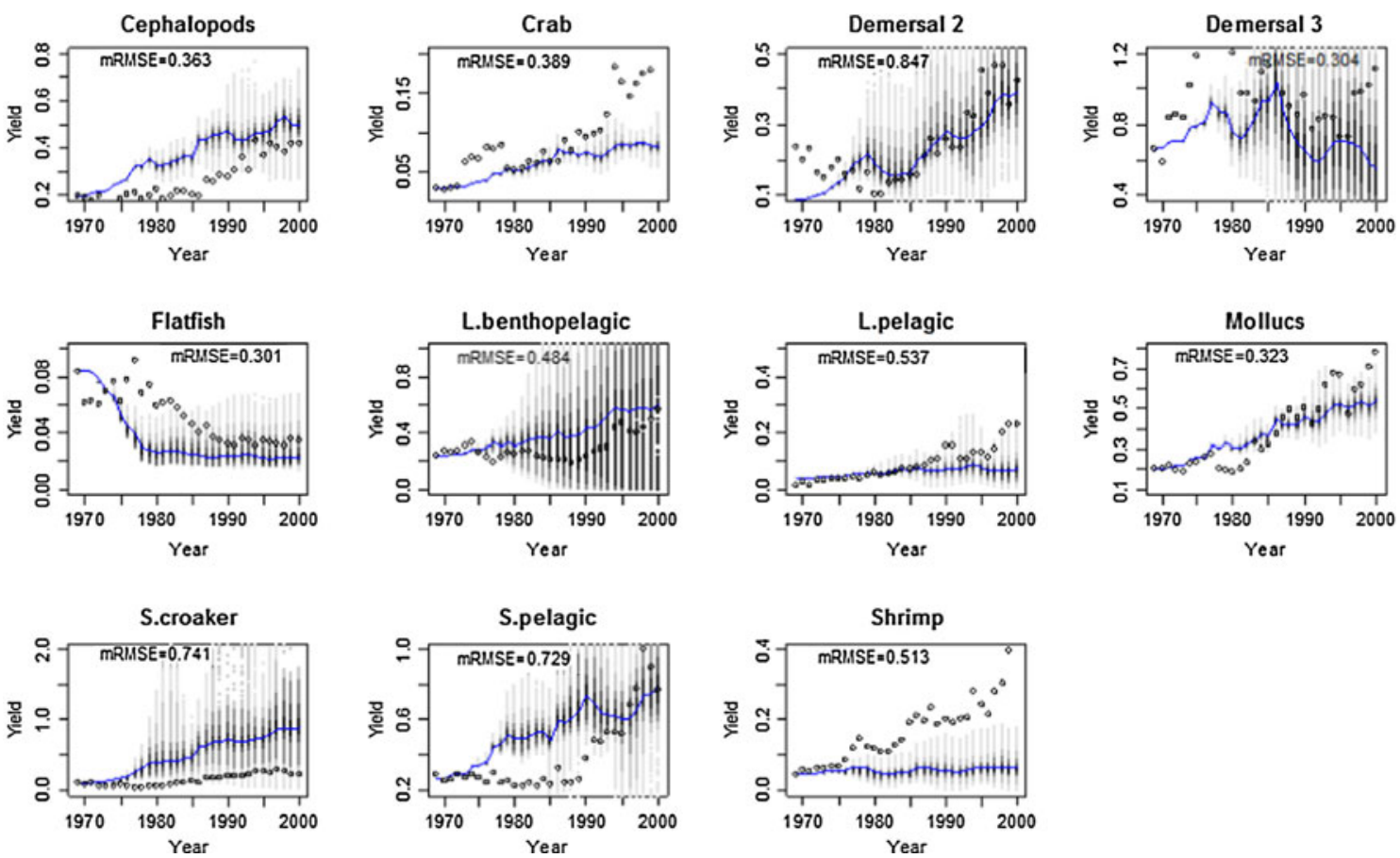

Fig. 3 Catch data $\left(\mathrm{t} \mathrm{km}^{-2}\right)$ fitting: predicted from the model (Line) versus observed trend (circles). The blues represent the median value of the predicted values. Different quantiles of the predict trend lines were shown using different depths of color gray

0.3 serving as default value for wasp-waist control, 0 implying bottom-up, and 1 implying top-down control; while in the version 5, vulnerability is scaled to range from 1 to infinity, with 2 serving as default value for wasp-waist control, 1 implying bottom-up, and infinity implying topdown control. Previous Ecosim publications had controversy in this vulnerable coefficient, for example, someone uses the default value; someone links the vulnerable coefficients with the trophic level of the species; while others use the model to estimate the vulnerable coefficients with no uncertainty considered.

According to Steneck et al. (2002), the top-down controls and bottom-up controls may vary because of the development of predator-prey relationship. Therefore, the vulnerability, defined as an index of top-down controls and bottom-up controls, is hard to be determined. In this study, we assumed the vulnerability follows the discrete distribution with a large variation:

$$
V= \begin{cases}1 & \gamma \in[0,03) \\ 10 \times \delta+1 & \gamma \in[0.3,06) \\ 10^{10} \times \delta+10 & \gamma \in[0.6,1]\end{cases}
$$

where both $\delta$ and $\gamma$ follow independent uniform distributions in $[0,1]$. In this way, the vulnerability has similar probabilities fall into above 3 discrete intervals, indicating the ecosystem has the similar probabilities of being bottom-up control, top-down control, and wasp-waist control. Although lacking of the information, the above distribution presents our best understanding of the vulnerability.

The results of time-series simulation were output by Ecosim and were tested using modified Root Mean Square Error statistics (mRMSE) to see how good a fit the simulation results make to the observe data, which are estimated using the following equation, and the value of mRMSE could be compared between groups simulated and a smaller mRMSE indicated a better fit.

$R_{i}=\frac{Y_{i}-P_{i}}{Y_{i}}$

$\operatorname{mRMSE}=\sqrt{\frac{1}{n} \sum_{i=1}^{n} R_{i}^{2}}$

where $Y_{i}$ is the observed value of the catch of group $i, P_{i}$ is the predicted value of the catch of group $i . n$ is the total number of functional groups.

Ecosystem indicators

No single indicator provides a complete picture of ecosystem state. Rather, a suite of indicators will be required, each focusing on different attributes, using different kinds of data, and spanning groups and processes with fast and slow dynamics.

(a) Kempton's $Q(Q 90)$ indices 


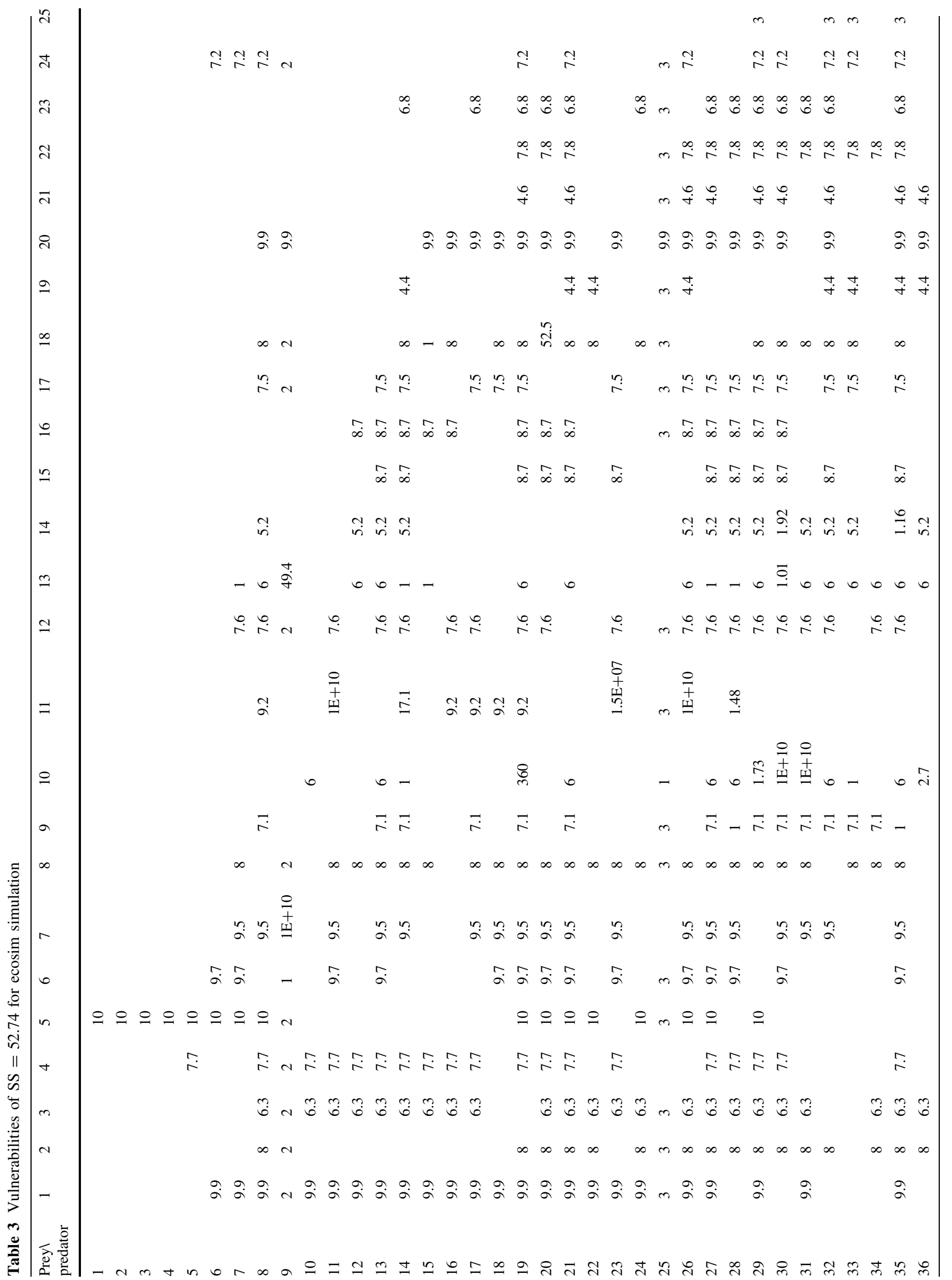




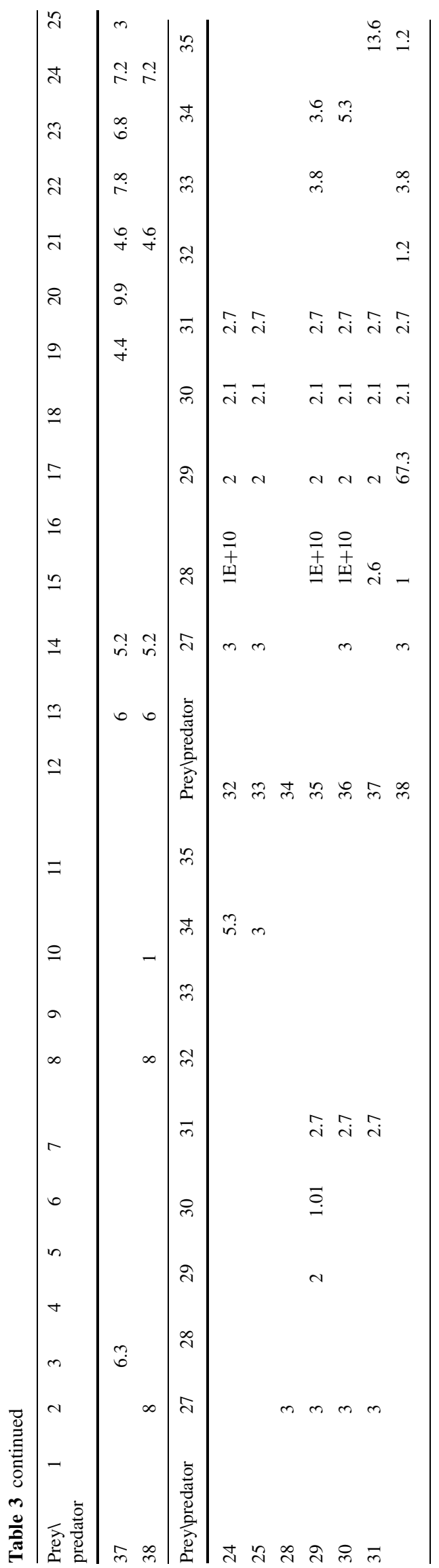

$Q 90$ index, a variant of the Kempton's $Q$ index developed by Kempton and Taylor (1976), could be used to track the changes on biodiversity under different fishing strategies (Ainsworth and Pitcher 2006). This index is determined between the 10th and 90th percentile from the slope of the cumulative functional group biomass curve (Eq. 6).

$Q 90=\frac{0.8 S}{\log \left(R_{2} / R_{1}\right)}$

where $S$ is the total number of functional groups; $R_{1}$ and $R_{2}$ are the biomass values of the 10th and 90th percentiles in the cumulative biomass distribution, representative.

(b) Mean trophic level of fishery catch

Although mean trophic level of catches might depend on fishing patterns (Essington et al. 2006), it has been considered an important ecological measure for evaluating the impacts of fishing on ecosystem (Pauly et al. 1998; Libralato et al. 2010). The mean trophic level of fishery catch $\left(\mathrm{TL}_{c}\right)$ that resulted from the time-series simulation was calculated using:

$\mathrm{TL}_{c}=\left[\frac{1}{Y_{t}}\right] \times \sum_{i=1}\left(Y_{i} \times \mathrm{TL}_{i}\right)$

where $Y_{t}$ is the total catch of year $t, Y_{i}$ is the catch of group i of year $t$, and $\mathrm{TL}_{i}$ is the trophic level of group $i$ of year $t$ (Pauly et al. 1998).

(c) Fishing-in-balance (FIB) index

The fishing-in-balance (FIB) index was defined as:

$\mathrm{FIB}_{t}=\log \left[Y_{t} \cdot(1 / \mathrm{TE})^{\mathrm{TL}_{c_{t}}}\right]-\log \left[Y_{0} \cdot(1 / \mathrm{TE})^{\mathrm{TL}_{c_{0}}}\right]$

This equation could be simplified to be Eq. 9 with the $\mathrm{TE}=10 \%$,

$\mathrm{FIB}_{t}=\log \left[Y_{t} / Y_{0}\right]+\mathrm{TL}_{c_{0}}-\mathrm{TL}_{c_{t}}$

where TE is the mean Trophic efficiency (Pauly and Christensen 1995) and 0 refers to any year used as the baseline to normalize the index (here is year 1969) (Pauly and Watson 2005). This definition implies that the FIB index:

- Increases $(>0)$ if: either 'bottom-up effect occurs', or if a geographic expansion of the fishery occurs.

- Decreases $(<0)$ if the fisheries withdraws so much biomass from the ecosystem that its functioning is impaired (Pauly and Watson 2005).

(d) Other ecological indicators

Other ecological synthetic indicators were also calculated to evaluate the ecosystem dynamics through the long-term periods, which could provide a summary of the ecosystem characteristics and are robust to evaluating the impacts of fishing (Rochet and Trenkel 2003; Fulton et al. 2005; 

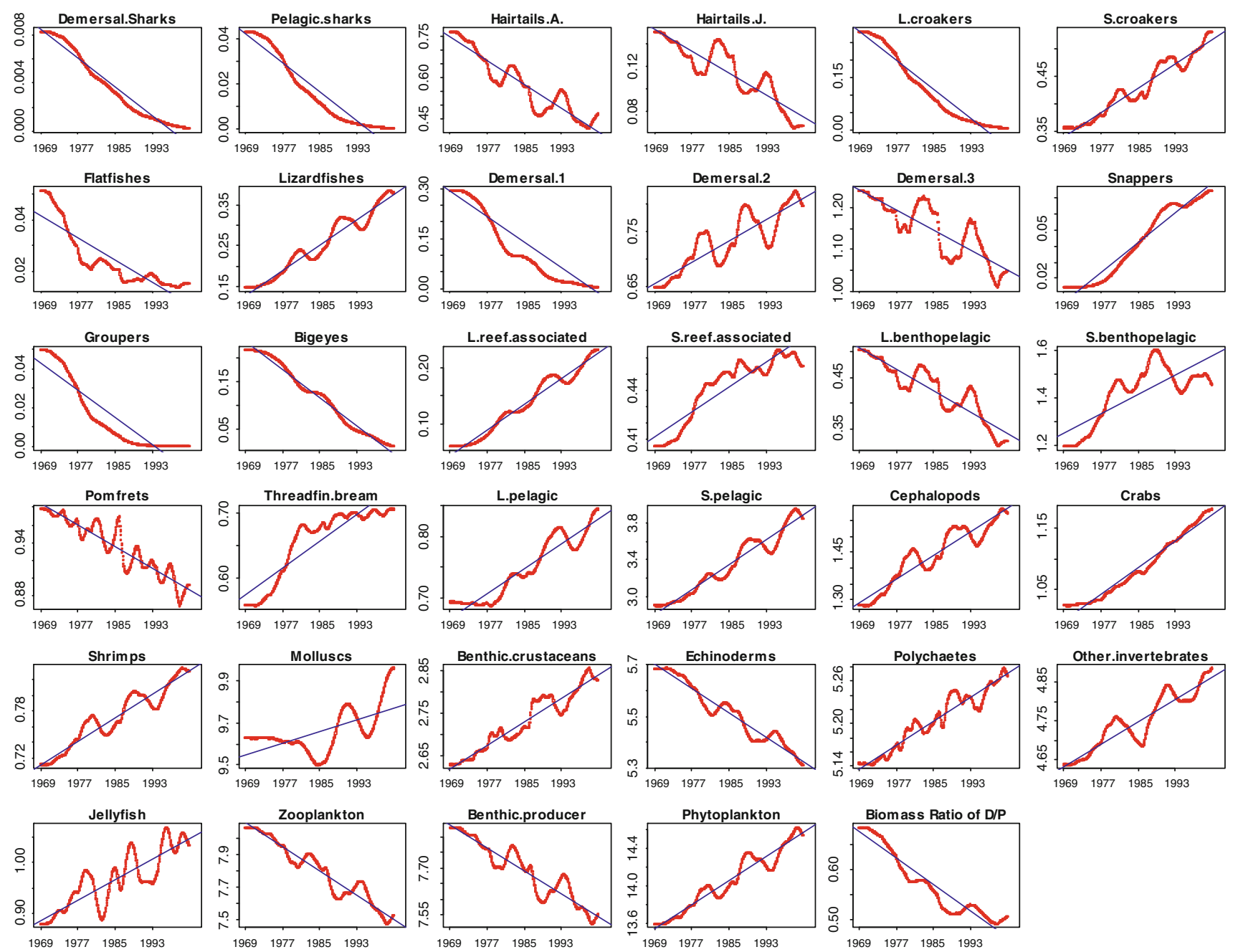

Fig. 4 Changes in biomass of fishes and invertebrates in the 32-year simulation (Unit: $\mathrm{t} \mathrm{km}^{-2}$ year $^{-1}$ ). Biomass ratio of $D / P$ represents the changes in the ratio of abundance between the dermersal fishes and pelagic fishes (lines on the plot are the regression lines)

Libralato et al. 2010). These indicators included overall system flows and biomass for the food web, indicators based on their ratios, measures of connectance within the food web and transfer efficiency as well as ecosystem maturity (Odum 1969; Christensen et al. 2005; Libralato et al. 2010). Table 1 listed the definition of these indicators and the abbreviation used in the following.

\section{Results}

Fitting the model to data

Table 2 represented the inputs and outputs of the models of 1970s and 2000s. Simulations were implemented to incorporating uncertainty in the vulnerability ratio. By running the Ecosim for 1,000 times, the uncertainty associated with the vulnerability ratio can be reflected in the predicted catch. The predicted catch trends portrayed by
1,000 simulations were plotted against the observed landing data for some commercial fish species (Fig. 3). The results of modified root mean standard error were also shown on the figures. Predicted catch trends from the model showed a statistically significant increase over time of almost all the groups, while a stabilizing state was shown for Flatfishes after the 1980s. The vulnerability values for the minimum SS (52.74) for the simulation were estimated and saved in Table 3.

Biomass and catch changes during the 32 year-simulation (384 months) were plotted in Figs. 4 and 5, respectively. Most demersal fish abundance had a huge decline during the 32-year simulation. The biomass and catch ratio between dermersal and pelagic fishes decreased over the simulation.

The Q90, TLc and FIB indices were estimated using the time-series simulation, which were used to evaluate the impact of fishing through the time period (Fig. 6). The FIB index increased during the time period due to the increase 

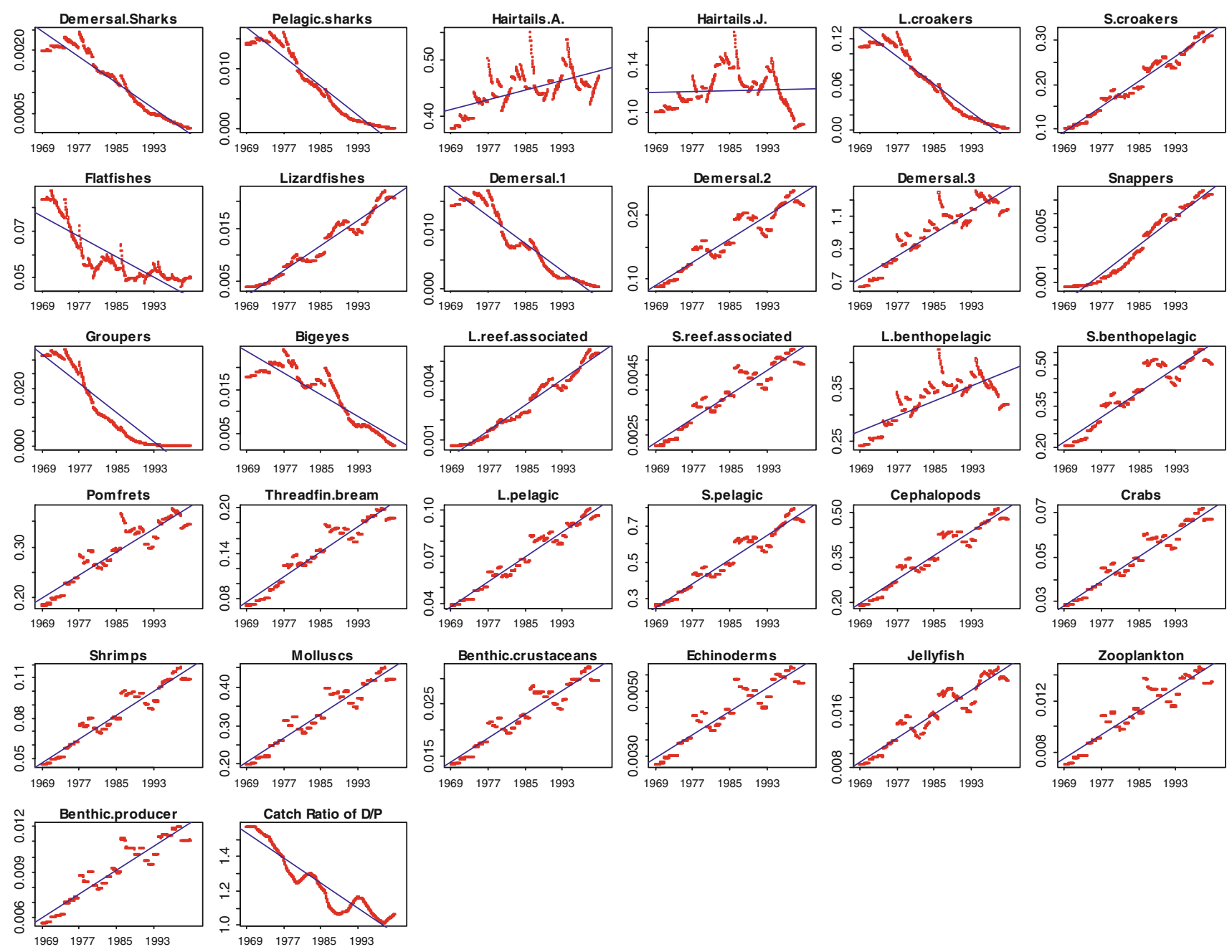

Fig. 5 Changes in catch of fishes and invertebrates in the 32-year simulation (Unit: $\mathrm{km}^{-2}$ year ${ }^{-1}$ ). Catch ratio of $D / P$ represents the changes in the ratio of yield between the dermersal fishes and pelagic fishes (lines on the plot are the regression lines)

in effort and the percentage of shrimps and small pelagic fishes in landings. The Total catch increased through the decades, with a decline of mean trophic level in catch. Kemptons $Q 90$ index decreased in the simulation, which indicated the degradation of biodiversity resulting from the fishing activity. The indicators had a slightly up trends from the early 1990s, which may benefit from the fishing closure carried out from June to September every year started from 1995.

Static comparison of the derived and proper 2000s model

For most functional groups, the end-state biomass of the derived 2000s model agrees closely with the proper 2000s model estimate (Table 4) and falls within the confidence interval suggested by the Ecopath pedigree ranking of data quality for the 2000s model. Confidence intervals associated with each degree of data quality are based on the default data pedigree settings used by Ecosim's Monte Carlo routine. The difference between the derived and proper 2000s model might also result from the environmental fluctuations that were not considered in the simulation.

Ecosystem development and the impacts of fishing

The derived 2000s model was also compared with the model of the 1970s in a number of ecosystem indicators (Fig. 7). Sum of production, sum of export and sum of the flows into detritus increased by 7.8, 65.6 and $26.3 \%$, respectively, while the total throughput did not change significantly through the time period. The total catch (TC) has a large increase of $87.5 \%$ with the large decline of 0.1 (3.14-3.04) in mean trophic level of the catch (TLc).

The indicators increasing with the increase of ecosystem maturity, such as Finn's cycling index (FCI), Finn's mean path length (FMPL) and overhead (O) decreased during the 

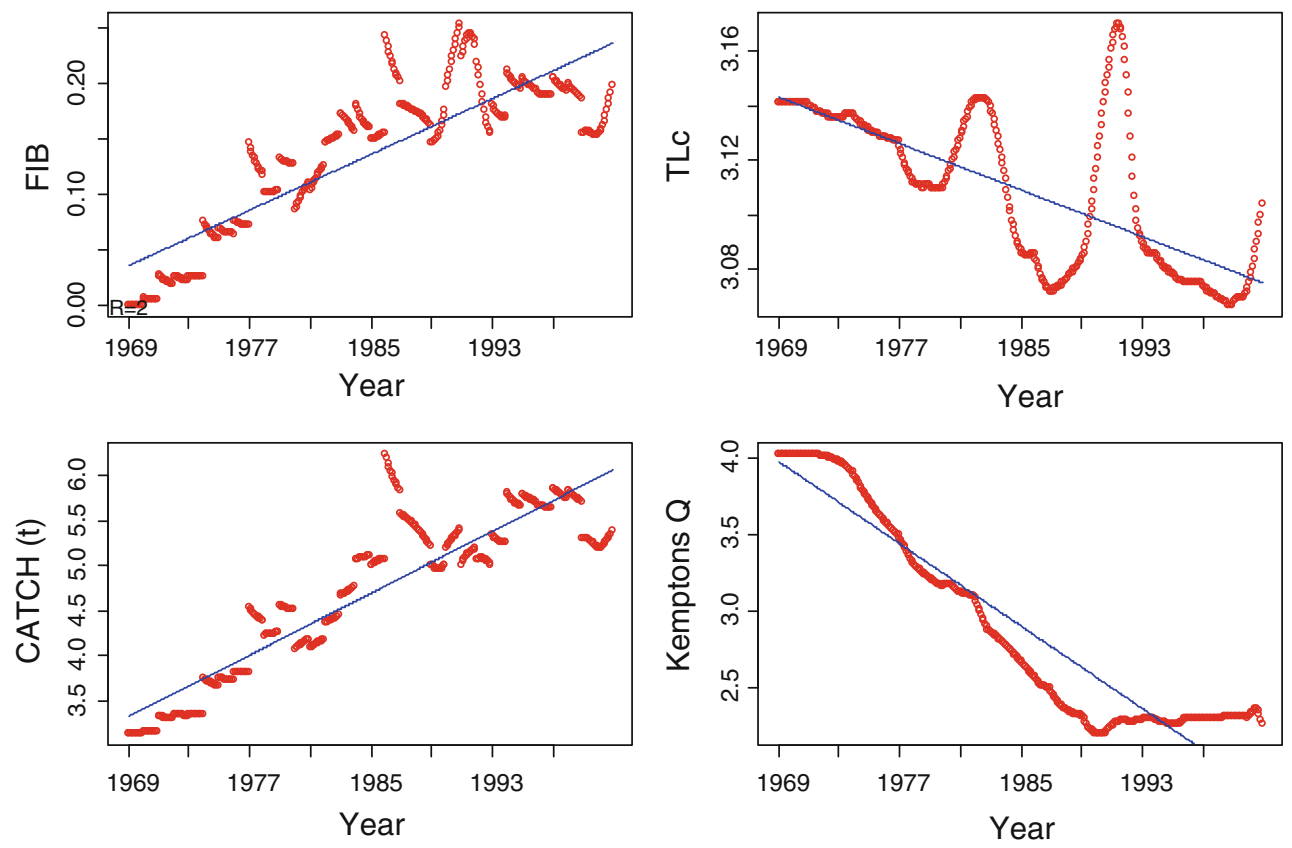

Fig. 6 Ecosystem indicators estimated from the Ecosim simulation (by month). The estimated trend is shown (line)

simulation period. Total primary production/total respiration (Tpp/TR), net system production (NSP), primary production/total biomass (PP/TB), ascendency (A) had increases of $85.9,65.6,25.9$ and $10.5 \%$, respectively, which also indicated the degradation of ecosystem development through the decades.

\section{Discussion}

In this study, using the relative fishing effort as the forcing function, the validity of the predictions from the ECSS model was supported by fitting the model with time-series of catch data. The sensitivity of vulnerability values in time-series simulation was also investigated. Twenty most sensitive vulnerabilities were determined by Ecosim time-series simulation, which did have strong impacts on the variation of simulation results. Through the catch trends of some groups simulated showed quite robust to the changing values of vulnerabilities, the low mRMSE value of simulated catch of the most functional groups and low SS (Sum of Squares) of fit in time-series simulations indicated the good prediction results of the model. Thus, the vulnerabilities of the minimum SS value estimated in this study could be available for evaluating alternative ecosystem-based management strategies (CH. Ainsworth, UBC Fisheries Centre, 2202 Main Mall, Vancouver, personal communication, 2009).

Overfishing is responsible for a wide variety of impacts on ecosystem communities. These include the modification of population structures and the imposition of stress conditions that force ecosystems to adapt to their changing environments (Watson and Pauly 2001; Myers and Worm 2003; Pauly and Watson 2005). Pauly et al. (1998) explained that "fishing down the food web" was a symptom of ecosystem deterioration when fish species of high trophic levels were overexploited and the fishery serially moves to species at the lower trophic level. The mean trophic level of the species groups reported in the fisheries statistics of the Food and Agricultural Organization declined from 1950 to 1994 in the face of overcapitalization and excess fishing effort (Pauly et al. 1998; Branch et al. 2010). The sign of fishing down the food web as well as fishing through the food web was also observed in the ECSS. Though the decline in abundance of most fish groups, especially the demersal species, was observed in the results of simulation, the magnitude of decrease in biomass of demersal fishes was much large than the scale decrease of pelagic species. The ecosystem had progressed toward being more pelagic-dominated from the demersaldominated system. The mean trophic level in catch decreased consistently with the decrease of fish biomass and the increase of the dominance of low trophic level organisms. This coincides with the decreasing trends in the diversity index of Kempton Q90 index and highlighted the decrease in abundance of various high TL organisms. This previously documented pattern, in combination with many other results of the present study, reflects the depletion of large predatory and gradual replacement of the K-selected species by the r-selected species (Coll et al. 2006, 2008).

The increase of flows to detritus had been previously suggested as an indicator of disruption in energy transfer from lower to higher trophic levels (Walsh 1981; Odum 
Table 4 Differences between group biomasses in the derived and proposed 2000s model

\begin{tabular}{|c|c|c|c|}
\hline Functional groups & De2000 & pro2000 & Difference $(\%)$ \\
\hline Marine mammals & 0.029 & 0.016 & -83.54 \\
\hline Seabirds & 0.003 & 0.002 & -36.36 \\
\hline Marine turtles & 0.004 & 0.002 & -100.00 \\
\hline Demersal Sharks & 0.002 & 0.005 & 60.00 \\
\hline Pelagic sharks & 0.015 & 0.017 & 7.78 \\
\hline Hairtails(A) & 0.407 & 0.099 & -311.11 \\
\hline Hairtails(J) & 0.128 & 0.251 & 49.00 \\
\hline Large croakers & 0.005 & 0.170 & 97.06 \\
\hline Small croakers & 0.434 & 0.144 & -201.39 \\
\hline Flatfishes & 0.012 & 0.022 & 45.45 \\
\hline Lizardfishes & 0.396 & 0.090 & -340.00 \\
\hline Demersal fishes 1 & 0.060 & 0.130 & 53.85 \\
\hline Demersal fishes 2 & 2.043 & 0.312 & -554.81 \\
\hline Demersal fishes 3 & 0.542 & 0.555 & 2.34 \\
\hline Snappers & 0.046 & 0.012 & -293.16 \\
\hline Groupers & 0.041 & 0.060 & 31.79 \\
\hline Bigeyes & 0.005 & 0.132 & 96.21 \\
\hline Large reef-associated fishes & 0.004 & 0.092 & 95.63 \\
\hline Small reef-associated fishes & 1.012 & 0.439 & -130.52 \\
\hline Large benthopelagic fishes & 1.028 & 0.560 & -83.57 \\
\hline Small benthopelagic fishes & 1.349 & 0.924 & -46.00 \\
\hline Pomfrets & 0.206 & 0.512 & 59.77 \\
\hline Threadfin bream & 0.245 & 0.340 & 27.94 \\
\hline Large pelagic fishes & 0.967 & 0.839 & -15.26 \\
\hline Small pelagic fishes & 2.630 & 3.772 & 30.28 \\
\hline Cephalopods & 1.238 & 0.780 & -58.72 \\
\hline Crabs & 1.360 & 0.623 & -118.30 \\
\hline Shrimps & 0.671 & 0.668 & -0.45 \\
\hline Molluscs & 7.839 & 9.510 & 17.57 \\
\hline Benthic crustaceans & 3.651 & 1.600 & -128.19 \\
\hline Echinoderms & 5.924 & 3.460 & -71.21 \\
\hline Polychaetes & 5.467 & 3.130 & -74.66 \\
\hline Other invertebrates & 5.835 & 4.160 & -40.26 \\
\hline Jellyfish & 4.361 & 2.150 & -102.84 \\
\hline Zooplankton & 6.459 & 5.572 & -15.92 \\
\hline Benthic producer & 6.668 & 7.830 & 14.84 \\
\hline Phytoplankton & 16.319 & 16.850 & 3.15 \\
\hline Detritus & 10.739 & 10.000 & -7.39 \\
\hline
\end{tabular}

1985; Shannon et al. 2009). In the ECSS, flows to detritus increased by $26.5 \%$ from 1969 to 2000 , indicating that the transfer of flow from lower to higher trophic levels decreased due to the ecosystem simplification, which results in a less efficient use of the system's energy, and overexploitation of the food web. These results were constant with the results observed by Zhang et al. (2006) and Xiong et al. (2010).
In addition, The Finn's cycling index (FCI) is defined as the recycled fraction of an ecosystem's throughput, which was shown to be an indication of the recovery time of the ecosystem by developing routes for nutrient conservation (Finn 1976, 1980; Vasconcellos et al. 1997). In Ecopath, it is defined as the part of the total flows (Christensen et al. 2005). The Finn's mean path length (FMPL) is similarly related to the recovery time of the ecosystem (Vasconcellos et al. 1997). The decrease of FCL and FMPL during the simulation period also implied the degeneration of the ecosystems.

Ascendency (A) and overhead (O) consisted the capacity of the ecosystem, which represented the network' potential for competitive advantage over other net work configurations and the system's reserved strength after the unexpected perturbations, respectively (Odum 1969; Christensen 1995). Thus, a system with high ascendency will be highly developed and a system with high overhead is more resilient and has strength in reserve (Heymans and Ulanowicz 2002; Heymans et al. 2004). In our case, the ascendency (A) increased and the overhead $(\mathrm{O})$ decreased during the simulated time period, which also indicate the degradation of ecosystem maturity and stability. According to Christensen (1995), total primary production/total respiration (Tpp/TR) is defined as the potential net primary production used in the ecosystem and in a mature and stable ecosystem, its value should be close to 1 . Net system production (NSP) and primary production/total biomass (PP/TB) should be decreasing in developing ecosystem based on the ecosystem stability theory of Christensen et al. (2005), while in the ECSS, these increased indicators through decades suggested the successional development of the system occurs in reverse.

Results obtained through the application of a trophodynamic process-oriented model with Ecosim had proved that the successional development of the system occurred in reverse by the dynamic simulation. The results also suggest that intense fishing activity during the period from 1969 to 2000 in the ECSS might be an important driver for the structural and functional changes in the marine ecosystem. Important changes in the ecosystem included a change in the biomass of several commercial and non-commercial species (observed and predicted by the model). The decrease of the mean trophic level of the landings and of biomass diversity and the increase of total flow to detritus are signs of the ecosystem changes in the East China Sea from 1969 to 2000. These results are consistent with the available information, and they point to a pattern of ecosystem degradation mainly due to high fishing activity (Chao et al. 2005). However, the fishing closure started from 1995 may have positive impacts on the ecosystem recovery.

Though this is the first shot taken on the uncertainty analysis on time series simulation using Ecosim, it is still a preliminary study and needs a lot of improvement. Like most studies of similar nature, deficiencies in available 


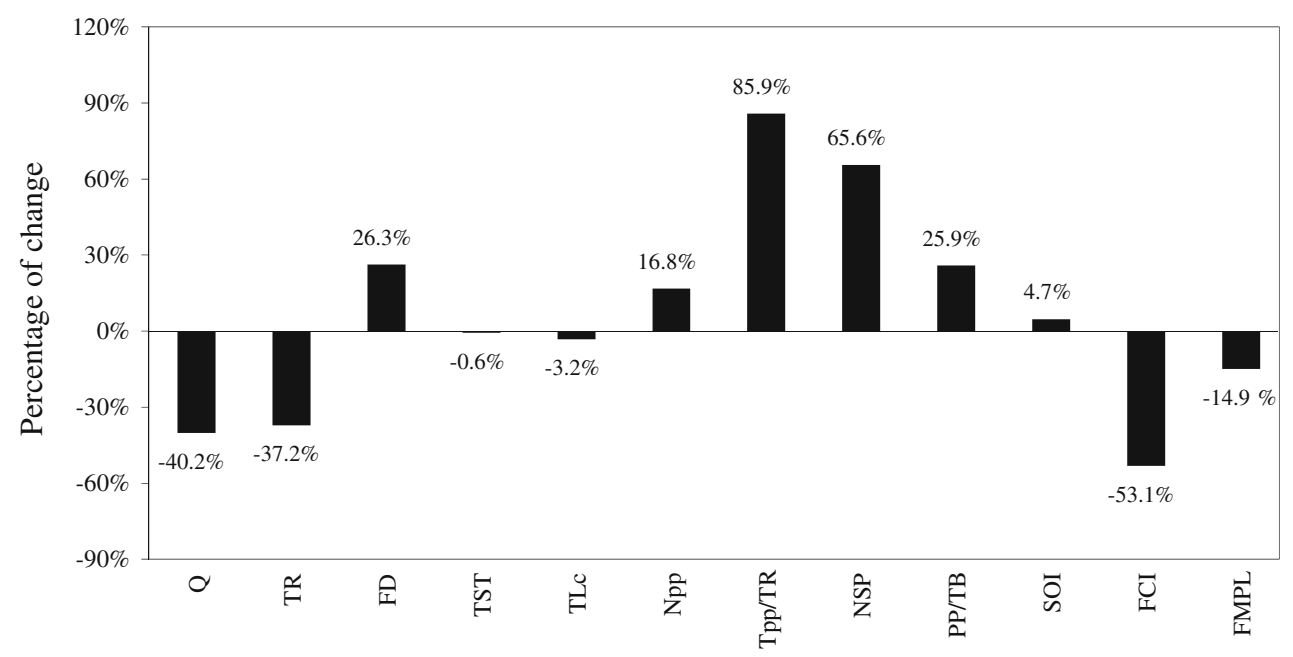

Fig. 7 The comparison of the total system properties between the 1970s model and the derived 2000s model of ECSS ecosystem (mean value). Q, sum of consumption; TR, sum of all respiratory flows; FD, sum of all flows into detritus; TST, total system throughput; TLc, mean trophic level of the catch; NPP, calculated total net primary

biological and fisheries data might influence the quality of this study. Part of the variations in the data could not be explained by the model, which might result from errors in data and, lack of consideration of environmental variables, and process errors. Another deficiency of this work is the only using catch data time series simulation instead of using both the biomass and catch data, which result from the lack of survey data. However, overall, the model developed in this study can provide realistic predictions of ecosystem dynamics and can be used as a reference model for evaluating alternative management strategies for the ECSS ecosystem. The approach developed in this study to incorporating uncertainty in one of the most important parameters, vulnerability, can be applied to modeling of dynamics of other ecosystems.

Acknowledgments The authors would like to thank Dr. Cameron Ainsworth in NOAA, Seattle, for his enthusiastic help for the questions and his supports on the model constructing and uncertainty analysis. Thank Dr. Shengfa Li from the East China Sea Fishery Research Institute for providing some of the data. Y. Li was supported by the Shanghai Education Commission Foundation for Excellent Young High Education Teacher of China (B-8101-09-0235) (B-821109-00-0202) and "Chen Guang" project supported by Shanghai Municipal Education Commission and Shanghai Education Development Foundation (D-8004-10-0206). Y. Zhang was partially supported by a Maine Sea Grant grant to Y. Chen. Thanks for the two anonymous reviewers for the constructive comments.

\section{References}

Ainsworth CH, Pitcher TJ (2006) Modifying Kempton's species diversity index for use with ecosystem simulation models. Ecol Indicator 6:623-630 production; Tpp/TR, total primary production/total respiration; NSP, net system production; PP/TB, total primary production/total biomass; SOI, system omnivory index; FCI, Finn's cycling index; FMPL, Finn's mean path length; A, ascendency; O, overhead

Botsford LW, Castilla JC, Peterson CH (1997) The management of fisheries and marine ecosystems. Science 277:509-515

Branch TA, Watson R, Fulton EA, Jennings S, McGilliard CR, Pabico GT, Ricard D, Tracey SR (2010) The trophic fingerprint of marine fisheries. Nature 468:431-435

Chao M, Quan W, Li C, Cheng Y (2005) Changes in trophic level of marine catches in the East China Sea region (in Chinese, with English summary). Mar Sci 29(9):51-55

Cheng J, Zhang Q, Li S (2006) Utilization on fishery stock of East China Sea Shelf and Yellow Sea. Science Technique Press, Shanghai

Christensen V (1995) Ecosystem maturity-towards quantification. Ecol Model 77(1):3-32

Christensen V, Walters C, Pauly D (2005) Ecopath with Ecosim: a user's guide. Fisheries center. University of British Columbia, Vancouver

Coll M, Palomera I, Tudela S, Sarda F (2006) Trophic flows, ecosystem structure and fishing impacts in the South Catalan Sea, Northwestern Mediterranean. J Mar Syst 59:63-96

Coll M, Libralato S, Tudela S, Palomera I, Pranovi F (2008) Ecosystem Overfishing in the ocean. PloS ONE 3(12):e3881. doi:10.1371/journal.pone.0003881

Cury PM, Shannon L (2004) Regime shifts in upwelling ecosystem: observed changes and possible mechanisms in the northern and southern Benguela. Prog Oceanogr 60:223-243

Dai TY (2004) Study in the ecological capacity of Fishery resources and capture fishery management in Fujian marine region. Science Press, Beijing

Essington TE, Beaudreau AH, Wiedenmann J (2006) Fishing through marine food webs. Proc Natl Acad Sci Biol 103(9):3171-3175

Finn JT (1976) Measures of ecosystem structure and function derived from analysis of flows. J Theor Biol 56:363-380

Finn JT (1980) Flow analysis of models of the Hubbard Brook ecosystem. Ecology 6:562-571

Fletcher WJ, Chesson J, Sainbury KJ, Hundloe TJ, Fisher M (2005) A flexible and practical framework for reporting on ecologically sustainable development for wild capture fisheries. Fisher Res 71:175-183

Fulton EA, Smith ADM, Punt AE (2005) Which ecological indicators can robustly detect effects of fishing? ICES J Mar Sci 62:540-551 
Heymans JJ, Ulanowicz RE (2002) Network analysis of the Everglades graminoid and cypress ecosystems. Ecol Model 49(1/2):5-23

Heymans JJ, Shannon LJ, Jarre A (2004) Changes in the northern Benguela ecosystem over three decades: 1970s, 1980s, and 1990s. Ecol Model 172:175-195

Kempton RA, Taylor LR (1976) Models and statistics for species diversity. Nature 262:818-820

Li Y (2009) Ecosystem modelling of the East China Sea Shelf ecosytems, PhD Dissertation. East China Normal University, Shanghai

Libralato S, Coll M, Tempesta M, Santojanni A, Spoto M, Palomera I, Arneri E, Solidoro C (2010) Food-web traits of protected and exploited areas of the Adriatic Sea. Biol Conser 143:2182-2194

Liu ZS, Liu Z (2004) China fisheries yearbook. China Agricultural Press, Beijing

Lotze HK, Lenihan HS, Bourque BJ, Brandbury RH, Cooke RG, Kay MC, Kidwell SM, Kirby MX, Peterson CH, Jackson JBC (2006) Depletion, degradation, and recovery potential of estuaries and coastal seas. Science 312:1806-1809

Myers RA, Worm B (2003) Rapid worldwide depletion of predatory fish communities. Nature 423:280-283

Odum EP (1969) The strategy of ecosystem development. Science 104:262-270

Odum EP (1985) Trends expected in stressed ecosystems. Bioscience 35(7):419-422

Pauly D, Christensen V (1995) Primary production required to sustain global fisheries. Nature 374:255-257

Pauly D, Watson R (2005) Background and interpretation of the 'Marine Trophic Index' as a measure of biodiversity. Philos Trans B 360:415-423

Pauly D, Christensen V, Dalsgaard J, Froese R, Torres FC Jr (1998) Fishing down marine food webs. Science 279:860-863

Rochet MJ, Trenkel VM (2003) Which community indicators can measure the impact of fishing? A review and proposals. Can J Fish Aquat Sci 60:86-99

Shannon LJ, Coll M, Neira S, Cury PM., Roux JP (2009) The role of small pelagic fish in the ecosystem. In: Checkley DM, Roy C,
Alheit J, Oozeki Y (eds) Climate change and small Pelagic Fish, pp 158-190

Steneck RS, Graham MH, Bourque BJ, Corbett D, Erlandson JM, Estes JA, Tegner MJ (2002) Kelp forest ecosystem: biodiversity, stability, resilience and future. Environ Conserv 29:436-459

Vasconcellos M, Mackinson S, Sloman K, Pauly D (1997) The stability of trophic mass-balance models of marine ecosystems: a comparative analysis. Ecol Model 100:125-134

Walsh JJ (1981) A carbon budget for overfishing off Peru. Nature 290:300-304

Walters CJ, Juanes F (1993) Recruitment limitation as a consequence of natural selection for use of restricted feeding habitats and predation risk taking by juvenile fishes. Can J Fish Aquat Sci 50:2058-2070

Walters CJ, Korman J (1999) Linking recruitment to trophic factors: revisiting the Beverton-Holt recruitment model from a life history and multispecies perspective. Rev Fish Biol Fish 9:187-202

Walters CJ, Martell SJ (2004) Harvest management for aquatic ecosystems. Princeton University Press, New Jersey

Walters CJ, Christensen V, Pauly D (1997) Structuring dynamic models of exploited ecosystem from trophic mass-balance assessment. Rev Fish Biol Fish 7:139-172

Watson R, Pauly D (2001) Systematic distortions in world fisheries catch trends. Nature 414:534-536

Xiong LF, Liu JH, Bai YZ, Shi XF, Zou JJ (2010) Distribution pattern of POC of the spring suspended matter in the Yellow Sea and the East China Sea (in Chinese with English Abstract). Mar Geo Quat Geol 30(3):7-14

Xu ZL, Zhang FY, Wang YL (2006) Abundance and distribution of appendicularia in the East China Sea (in Chinese with English Abstract). Mar Fish 28(2):94-98

Zhang YS, Zhang FJ, Guo XW, Zhang MP (2006) Autumn flux of particle setting observed at three representative stations in the East China Sea (in Chinese with English Abstract). Oceanol Limnol Sin 37(1):29-34

Zheng Y, Wang Y, Chen Y (2003) The survey reports of East China Sea Shelf. Science Press, Shanghai 